Check for updates

Cite this: RSC Adv., 2019, 9, 33733

Received 27th August 2019

Accepted 28th September 2019

DOI: $10.1039 / c 9 r a 06763 a$

rsc.li/rsc-advances

\section{A reservoir-damage-free encapsulated acid dually controlled by hydrogen ion concentration and temperature}

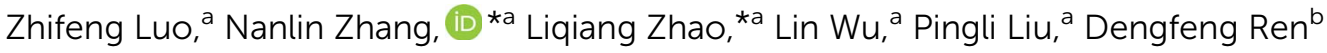 \\ and Chun Qing ${ }^{c}$
}

Oil and gas exploration and development extends from medium-low temperatures to high and ultra-high temperatures with the development of the oil and gas industry. High-temperature deep carbonate reservoir acid fracturing has introduced more stringent requirements, a slower chemical reaction rate and excellent dissolution performance of acid systems, which means that the acid system should still have a certain dissolution ability above $135{ }^{\circ} \mathrm{C}$. A novel water-soluble encapsulated acid (EA), dual controlled by hydrogen ion concentration and temperature, was developed to exploit ultra-high-temperature carbonate reservoirs. The encapsulating material was insoluble and isolated the internal solid acid at high $\mathrm{H}^{+}$ion concentrations and low temperatures, but the solid acid was released as the encapsulating material was dissolved at low $\mathrm{H}^{+}$ion concentrations and high temperatures. This unique performance was characterized by ESEM, TGA, FTIR, NMR, mechanical performance, solubility, etching performance, and etching fracture conductivity. All the scientific results show that this EA can be applied as a longdistance etching acid controlled by $\mathrm{H}^{+}$ion concentration and temperature, without the need for a thickener and emulsifier to reduce the reaction between the rock and the acid near the wellbore. The test results demonstrated that the solid acid had good thermal stability at $135{ }^{\circ} \mathrm{C}$, the encapsulation material was almost insoluble in high acid concentrations ( $>14 \%)$ at any temperature, and the solid acid began to release when the concentration of hydrochloric acid was less than $14 \%$ and the temperature was higher than $95{ }^{\circ} \mathrm{C}$. The rock etching and dissolution behavior was better than that of $\mathrm{HCl}$ with the same concentration and the etching fracture conductivity was improved by supplementing the consumption of $\mathrm{H}^{+}$ions when etching rock. The encapsulating material is completely dissolved after acid fracturing, avoiding reservoir damage by the residue. The described EA is a promising approach for application in acid fracturing of carbonate reservoirs at ultra-high temperature $\left(>135^{\circ} \mathrm{C}\right)$.

\section{Introduction}

With the development of the global oil and gas industry, oil and gas exploration and development extends from shallow layers to deep layers and ultra-deep layers and changes rapidly from medium-low temperatures to high and ultra-high temperatures. ${ }^{1-3}$ High-temperature deep carbonate reservoir acid fracturing has introduced more stringent requirements, ${ }^{4-6}$ a slower chemical reaction rate and excellent dissolution performance of acid systems, which means that the acid system still should have a certain dissolution ability above $135{ }^{\circ} \mathrm{C}^{7-9}$ Existing acids for high temperatures with a slow chemical reaction rate include emulsified acids, ${ }^{10,11}$

${ }^{a}$ State Key Laboratory of Oil and Gas Reservoir Geology and Exploitation, Southwest Petroleum University, Chengdu 610500, P. R. China. E-mail: nanlin_zhang@163. com; zhaolq@163.vip.com

${ }^{b}$ PetroChina Tarim Oil Company, Korla, 841000, P. R. China

${ }^{c}$ Southwest Oil \& Gas Field Company, CNPC, Chengdu, 610500, China organic acids ${ }^{12,13}$ and cross-linked acids. ${ }^{14}$ Although these acid systems have a certain slow chemical reaction rate performance, they are in direct contact with the acid fracturing pipelines and therefore must be treated with corrosion inhibitor additives. ${ }^{15-17}$ The concept of encapsulated acids, which use encapsulating materials to cover solid hydrochloric acid, ${ }^{18}$ nitric acid ${ }^{19}$ and citric acid, ${ }^{20-22}$ has been researched, as has the isolation of solid acids by means of encapsulation methods. The penetration depth of acids has been increased by the temperature and time-controlled dissolution performance of different encapsulating materials. Although EAs can solve the problem of corrosion, they are limited by drawbacks such as the low effective $\mathrm{H}^{+}$ion concentration of acids, poor thermal resistance, and the short penetration depth of the acids. According to previous studies indicating that a waterinsoluble $\mathrm{EA}^{23}$ may cause formation damage owing to the insoluble matter, improvement of the thermal resistance, mechanical strength, toughness and solubility of encapsulating materials can enhance the penetration of the EA and 
avoid the formation damage. In the present study, the tetrapolymer used as the encapsulating material, known as the $\mathrm{H}^{+}$ ion-temperature responsive coating material (HTRCM), was prepared by copolymerization of acrylamide monomers, tertbutyl allyl carboxylate monomers, diallylamine monomers, and allyl alkyl polyether monomers. The solid hydrochloric acid was encapsulated to prepare the EA. Therein, acrylamide, tert-butyl allyl carboxylate, diallylamine, and allyl alkyl polyether were used as backbone monomers, acid-resistant monomers, strength monomers, and toughness monomers, respectively.

The proposed EA was carried by the acidic solution. The acidic solution has two functions; carrying the EA and also etching the surface of the rock in the near-well region. Unlike other EAs, ${ }^{18-22}$ the release of the proposed EA is dual controlled by the $\mathrm{H}^{+}$ion concentration and the temperature. With low temperatures $\left(<95{ }^{\circ} \mathrm{C}\right)$ and high $\mathrm{H}^{+}$ion concentrations of the carrying fluid $(>14 \%)$, the encapsulating material should maintain its structural integrity, isolate the carrying fluid from the solid hydrochloric acid (SHA), and prevent the solid hydrochloric acid from being dissolved. With the increase of the temperature $\left(>95{ }^{\circ} \mathrm{C}\right)$ and a decrease in the $\mathrm{H}^{+}$ion concentration $(<14 \%)$, the encapsulating material dissolves and releases the solid hydrochloric acid. Ionization produces $\mathrm{H}^{+}$ions, meaning that the $\mathrm{H}^{+}$ion concentration of the acidic solution is restored. During this process, the $\mathrm{H}^{+}$ion concentration undergoes a dynamic change process, as illustrated in Fig. 1:

The above characteristics of the proposed EA made good use of the hydraulic fracture with the low temperature and high $\mathrm{H}^{+}$ion concentration in the near-well region as well as at the high temperature and low $\mathrm{H}^{+}$ion concentration in the farwell region. ${ }^{\mathbf{2 4 2 5}}$ In the near-well region, $\mathrm{H}^{+}$ions of the acidic solution are used to etch the fracture surface without releasing the SHA. In the far-well region, the SHA is released and etches the fracture faces, effectively increasing the penetration depth of the acid. The carrying fluid etches the fracture faces in the near-well region ${ }^{26}$ and the EA etches the fracture faces in the far-well region, effectively increasing the effective penetration distance of acid fracturing, as shown in Fig. 1. Therefore, the proposed EA is of great potential significance for the acid fracturing reconstruction of hightemperature deep reservoirs.

\section{Methodology}

\subsection{Materials}

Hydrazine hydrate $\left(\mathrm{N}_{2} \mathrm{H}_{4} \cdot \mathrm{H}_{2} \mathrm{O}\right)$, hydrochloric acid ( $\left.\mathrm{HCl}\right)$, acrylamide monomers (AL), tert-butyl allyl carboxylate monomers (AC), diallylamine monomers (DL), allyl alkyl polyether monomers (AAP), absolute ethanol (AE), anion polyacrylamide (AP), ethyl acetate (EAC) and dichloromethane (DE) were purchased from Kelong in Chengdu. All chemicals and reagents were utilized without further purification.

\subsection{Preparation of SHA, HTRCM, and EA}

The preparation process was divided into three steps, comprising the preparation of SHA, the preparation of the encapsulating material HTRCM and the preparation of the EA. The process is illustrated in Fig. 2:

The first step was the preparation of the SHA. $10 \mathrm{~mL}$ of hydrazine hydrate (concentration: $80 \%$ ) and $25 \mathrm{~mL}$ of concentrated hydrochloric acid (concentration: 36\%) were placed in a beaker. After reaction at $15{ }^{\circ} \mathrm{C}$ for 45 minutes, suction filtration was applied to achieve solid-liquid separation at $20^{\circ} \mathrm{C}$ with a suction filtration time of $10 \mathrm{~min}$. The separated solid was then dried in a vacuum drying oven at $80{ }^{\circ} \mathrm{C}$ for $2 \mathrm{~h}$. Finally, the prepared solid hydrochloric acid $\left(\mathrm{N}_{2} \mathrm{H}_{4} \cdot 2 \mathrm{HCl}\right)$ was stored for use.

The second step was the preparation of the encapsulation material, HTRCM. $20 \mathrm{~mL}$ of AE, $4 \mathrm{~g}$ of AL, $5 \mathrm{~g}$ of AC, $0.5 \mathrm{~g}$ of PL, and $0.5 \mathrm{~g}$ of AAP were mixed in a beaker and stirred at $55^{\circ} \mathrm{C}$ for $10 \mathrm{~h}$. The mixture then was precipitated with AE. Then the prepared HTRCM encapsulating material was dried in a vacuum drier and stored for use.

The third step was the preparation of the EA. $10 \mathrm{~mL}$ of AP and $10 \mathrm{~mL}$ of $\mathrm{AE}$ mixture were stirred to complete dissolution in a beaker. The SHA prepared during the first step was added into the beaker and stirred at a constant rate. After adding EAC, AP precipitated and adhered to the surface of the SHA as a protective coating. Then the precipitated solid was filtered, dried at $80{ }^{\circ} \mathrm{C}$ for $24 \mathrm{~h}$, and placed in a coating pan. The coating pan was rotated at a speed of $80 \mathrm{rpm}$ and a temperature of $70{ }^{\circ} \mathrm{C}$. HTRCM was mixed with AE to prepare a spray solution, which then was evenly sprayed on the solid surface to obtain the EA.

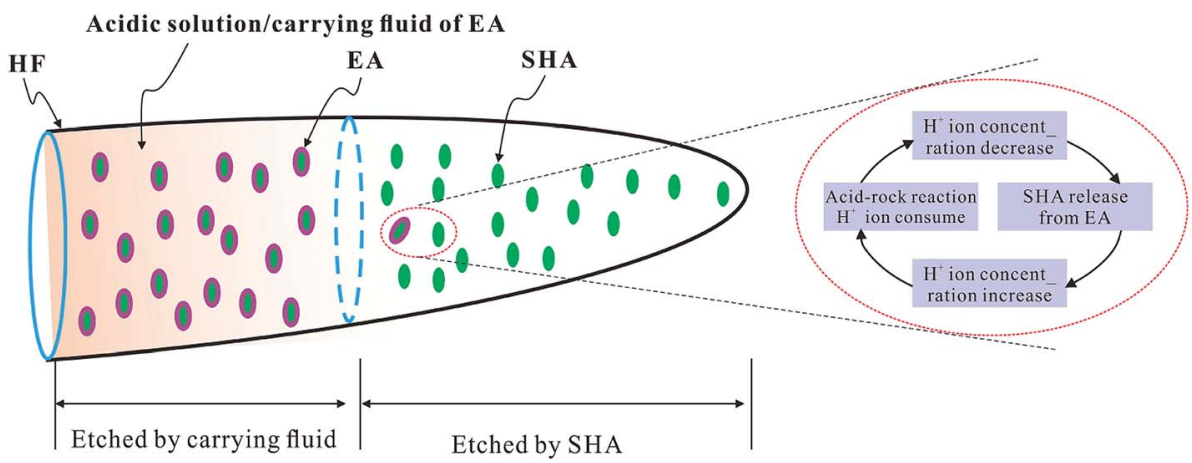

Fig. 1 The dynamic process of the $\mathrm{H}^{+}$ion concentration in the acidic solution and EA migration to the far end of the fracture (HF: hydraulic fracture, EA: encapsulated acid, SHA: solid hydrochloric acid). 

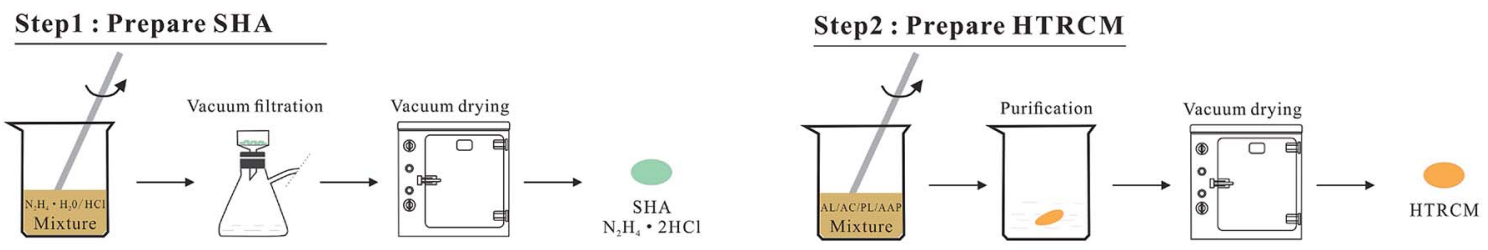

\section{Step3: Prepare EA}

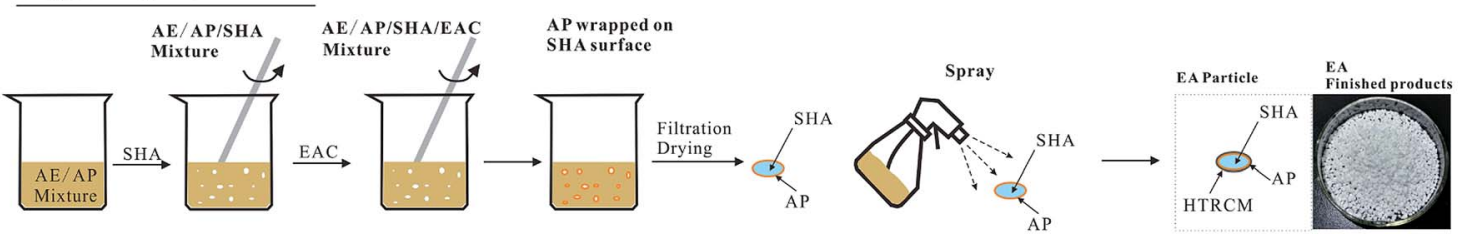

Fig. 2 Flow chart of the preparation of SHA, HTRCM, and EA.

\subsection{ESEM and energy spectrum analysis of EA}

An FEI Quanta 450 environmental scanning electron microscope with an attached ESAX X-ray energy spectrometer was used to observe the micromorphology of the EA surface and analyze the elemental composition.

\subsection{Thermogravimetric analysis of the SHA}

The SHA described in this paper was a pure substance that was formed by replacing the water molecules in hydrazine hydrate with hydrochloric acid. Its thermogravimetric analysis was related to the parameters of the encapsulation material, the effective concentration of $\mathrm{H}^{+}$ions, etc. It was necessary, therefore, to test the thermal stability of the SHA. A simultaneous thermal analyzer (NETZSCH STA449 F3) was used to test the weight change and heat change of the SHA in the range of 45$400{ }^{\circ} \mathrm{C}$.

\subsection{FTIR analysis of the HTRCM}

$\mathrm{KBr}$ and HTRCM were mixed to uniformity at a mass ratio of $\mathrm{KBr}: \mathrm{HTRCM}=50: 1$ before being ground and compressed. The infrared spectrum was measured using a WQF-520A FTIR. The testing temperature was $25^{\circ} \mathrm{C}$ and the number of scans was 16.

\subsection{NMR analysis of the HTRCM}

$20 \mathrm{mg}$ of the HTRCM sample and $1.00 \mathrm{~mL}$ of $\mathrm{D}_{2} \mathrm{O}$ were added to an EP tube. After the mixture had dissolved completely, $0.60 \mathrm{~mL}$ samples were taken to the $5 \mathrm{~mm}$ NMR tube. A Bruker Avance III $400 \mathrm{MHz}$ NMR spectrometer was used to test the ${ }^{1} \mathrm{H}$ NMR spectrum of the sample with the liquid BBO normal-phase observation broadband probe.

\subsection{Mechanical performance test of the HTRCM}

HTRCM was used as the encapsulating material for the EA, and when the EA was injected into the reservoir, it was affected by pressure, friction, etc. The HTRCM needs to have a certain filmforming ability and mechanical strength. Hence, the mechanical performance of the HTRCM was tested.
The material was dissolved in AE to prepare a $0.05 \mathrm{~g} \mathrm{~mL}^{-1}$ solution, which was poured into a polystyrene dish and placed in an oven at $35^{\circ} \mathrm{C}$, allowing the $\mathrm{AE}$ to evaporate to obtain a film formed by the HTRCM.

The film formed by the HTRCM was cut into samples of about $5.0 \mathrm{~mm}$ in width. The tensile strength and maximum load of the samples were measured using a CWT6104 electronic universal testing machine (Meters Industrial Systems Co., Ltd.). The samples were tested three times. The average tensile stress was taken as the final result.

\subsection{Dissolution test of the HTRCM}

The dissolution of the HTRCM at room temperature $\left(25^{\circ} \mathrm{C}\right)$ was studied using different polar solvents. Appropriate amounts of the HTRCM were accurately weighed and added into five $2.0 \mathrm{~mL}$ centrifuge tubes. Next, $1.5 \mathrm{~mL}$ of various solvents, which were $\mathrm{AE}$, EAC, DE, deionized water, and $\mathrm{NaOH}$ solution $\left(0.01 \mathrm{~g} \mathrm{~mL}^{-1}\right)$, was added into the tubes. After storage at $25^{\circ} \mathrm{C}$ for $24 \mathrm{~h}$, the dissolution states of all materials were observed. All the solutions in the centrifuge tubes were filtered by a 150 mesh screen and the obtained residues were dried at $80{ }^{\circ} \mathrm{C}$ under vacuum for 2 days. The dried HTRCM was weighed and the material residual rate was calculated using eqn (1).

$$
R=\frac{m_{\mathrm{n}}}{m_{\mathrm{p}}}
$$

where $R$ refers to the material residual rate and $m_{\mathrm{p}}$ and $m_{\mathrm{n}}$ refer to the mass of HTRCM before and after the dissolution experiment, respectively.

As the EA was carried by the acidic solution, the dissolution performance of the HTRCM in concentrated hydrochloric acid (mass fraction $37 \%)$ and sodium hydroxide solution $\left(0.01 \mathrm{~g} \mathrm{~mL}^{-1}\right)$ was investigated. The method used was: two appropriate amounts of HTRCM were weighed and put into two PTFE reactors with high-pressure reaction kettles. $15.00 \mathrm{~mL}$ samples of the concentrated hydrochloric acid and the sodium hydroxide solution were taken and added to the above PTFE reactors, and the reaction kettles were sealed. The reaction kettles were put into an electric blast drying oven at a constant temperature of $135^{\circ} \mathrm{C}$ for 3 hours, after which the reaction kettles were taken out and cooled to 
room temperature. Then all the solutions in the reaction kettles were filtered using a 150 mesh screen and the obtained residue was dried at $80{ }^{\circ} \mathrm{C}$ under vacuum for 2 days. The dried HTRCM was weighed accurately and the material residual rate was calculated using eqn (1).

\subsection{Effect of the $\mathbf{H}^{+}$ion concentration in the carrying fluid on the release of $\mathrm{EA}$}

When the $\mathrm{H}^{+}$ion concentration in the carrying solution was high, the HTRCM was insoluble and encapsulated the SHA. When the $\mathrm{H}^{+}$ion concentration in the carrying fluid decreased, the HTRCM was gradually damaged and water in the carrying fluid penetrated into the EA through the HTRCM, dissolving and releasing SHA. The effect of the acid concentration on the SHA release was tested. The test method was as follows: (1) $20 \mathrm{~mL}$ samples of hydrochloric acid with concentrations of $0 \%$, $1 \%, 2 \%, \ldots, 28 \%, 29 \%$, and $30 \%$ were added separately to the PTFE reactor. (2) EA with an accurate mass of $m_{\mathrm{p}}$ was put into the acid with different concentrations from step (1). (3) The PTFE reactor was heated at $135{ }^{\circ} \mathrm{C}$ for 1 hour and then taken out. It was filtered using a 150 mesh screen to obtain the solid. (4) The obtained solid was dried at $80{ }^{\circ} \mathrm{C}$ under vacuum until the solid weight was constant. (5) The obtained solid was weighed, the mass was recorded as $m_{\mathrm{n}}$ and the mass residual rate was calculated according to eqn (1).

\subsection{Temperature influence on the SHA release}

Temperature can affect the acid release rate by affecting the dissolution performance of the HTRCM in the carrying fluid. The effect of temperature on the rate of EA release was therefore investigated. The test method was as follows: (1) $20 \mathrm{~mL}$ samples of hydrochloric acid with concentrations of $c(c=11 \%, 12 \%$, $13 \%, 14 \%, 15 \%, 16 \%)$ were added separately to the PTFE reactor. (2) EA with an accurate mass of $m_{\mathrm{p}}$ was put into the hydrochloric acid. (3) The PTFE reactor was heated in an electric blast drying oven separately at a constant temperature of $T$ (where $\mathrm{T}=85^{\circ} \mathrm{C}, 95^{\circ} \mathrm{C}, 105^{\circ} \mathrm{C}, 115^{\circ} \mathrm{C}, 125^{\circ} \mathrm{C}$, and $135^{\circ} \mathrm{C}$ ) for $1.0 \mathrm{~h}$, and then the solution was filtered using a 150 mesh screen to obtain the remaining solid. (4) The obtained solid was dried at $80{ }^{\circ} \mathrm{C}$ under vacuum until the weight of the solid was constant and the mass was recorded as $m_{\mathrm{n}}$. (5) The mass residual rate was calculated according to eqn (1).

\subsection{Test of the SHA content in the EA}

As shown in Fig. 3, the EA was a particulate solid with a particle size of 10-20 mesh. The EA structure was divided into three layers, with the innermost layer being SHA and the outermost layer being the HTRCM, and the AP between them. The function of the HTRCM was to isolate the SHA, preventing the SHA from reacting in the near-well area. When the EA entered the far end of the fracture, the $\mathrm{H}^{+}$ion concentration in the carrying fluid decreased and the encapsulating layer structure was destroyed, releasing the SHA to etch the fracture surface. Therein, the SHA content determined the etching performance on the fracture surface at the far end. The SHA content in the EA then was determined using a titration method.
The determination method was as follows: (1) an accurate amount $\left(M_{1}\right)$ of $\mathrm{NaOH}$ was weighed and then dissolved in deionized water $(50 \mathrm{~mL})$. The solution was transferred to a volumetric flask with $50 \mathrm{~mL}$ capacity and made up to $50 \mathrm{~mL}$ with sodium hydroxide solution. (2) A small amount of SHA was added into $20 \mathrm{~mL}$ of the sodium hydroxide solution prepared in step (1) and reacted for $20 \mathrm{~min}$. The product from step (2) was titrated against hydrochloric acid with a concentration, $c_{1}$, of about $0.25 \mathrm{~mol} \mathrm{~L}^{-1}$ until the $\mathrm{pH}$ value was 7 , with the volume of hydrochloric acid consumed recorded as $V_{1}$. (3) EA with the same mass as the SHA used in step (2) was added slowly into another $20 \mathrm{~mL}$ of sodium hydroxide solution and reacted for $20 \mathrm{~min}$. After adding one drop of methyl orange, the product from step (3) was titrated against hydrochloric acid with a concentration of about $0.25 \mathrm{~mol} \mathrm{~L}^{-1}$ until the light red solution turned colorless, with the volume of hydrochloric acid consumed recorded as $V_{2}$. The SHA content of the EA was calculated with eqn (2).

$$
P_{\mathrm{SHA}}=\frac{0.4 \times M_{1}-V_{1} \times c_{1} \times 40 / 1000}{0.4 \times M_{1}-V_{2} \times c_{1} \times 40 / 1000}
$$

\subsection{Etching performance tests}

The etching performance by the $\mathrm{HCl}$ and the EA on the rock was using the following procedure: (1) 12 rock blocks were polished to produce a smooth surface. The surface areas of those rocks were approximately equal, and all rock blocks were put in a drying oven for two days. (2) Two hydrochloric acid solutions of $500 \mathrm{~mL}$ with a concentration of about $15 \%$ were prepared, to one of which was added a certain amount of EA, so that the EA mass fraction reached 5\%. (3) All acid solutions were put in 12 reaction vessels follow the mixing ratio of $10 \mathrm{~mL}: 1 \mathrm{~g}$ with the rock blocks. Six pieces of rock block were exposed to the two acid solutions and each was numbered, and the reaction time recorded. Then the acid solutions and rock blocks were placed in a water bath to maintain the temperature at $90{ }^{\circ} \mathrm{C}$ while recording the reaction time. The rock blocks were taken out after reaction times of $10 \mathrm{~min}, 20 \mathrm{~min}, 30 \mathrm{~min}, 40 \mathrm{~min}, 50 \mathrm{~min}$,

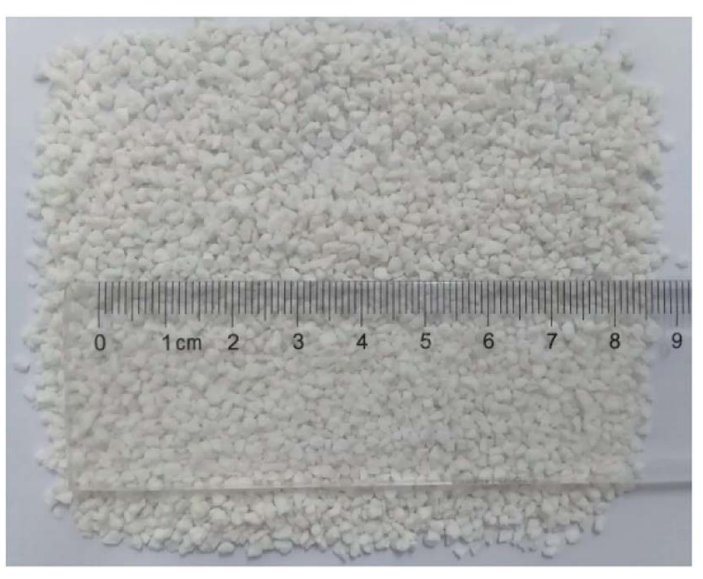

Fig. 3 Appearance and size distribution of the EA. 
$60 \mathrm{~min}, 120 \mathrm{~min}$, and $180 \mathrm{~min}$, after which they were washed, dried and measured. The residual acid concentrations were determined by titration and the rocks were weighed and their weights recorded. The detailed experimental parameters are shown in Table 1.

\subsection{Etched fracture conductivity test of the EA}

Acid-etched fracture conductivity is one of the most important evaluation criteria for the acid fracturing effect. ${ }^{27,28}$ The acidetched fracture conductivity test procedure (the theoretical analysis of the experiment refers to the work by Asadollahpour et $a .^{27}$ ) was performed using the acid-etched fracture conductivity equipment (Fig. 4) produced by Chengdu Core Technology Co., Ltd in Sichuan Province to evaluate the performance of the EA. The experimental steps were as follows: (1) hydrochloric acid with concentrations of $5 \%, 10 \%, 15 \%$, and $20 \%$ was prepared in duplicate, and to one of these was added an appropriate amount of EA to make $\omega_{\mathrm{CCRSA}}=5 \%$. The acid formula is shown in Table 2. (2) A total of 16 rock plates with dimensions of $15 \times 10 \times 2 \mathrm{~cm}$ were manufactured and numbered 1-8. Eight pairs of rock plates were placed into the core holder. (3) The core holder was connected, the holder heating system was opened and the temperature was set to $120^{\circ} \mathrm{C}$. (4) A standard brine solution and the acid system were poured into the corresponding liquid tanks, the heating jacket

Table 1 Parameter of etching performance tests

\begin{tabular}{|c|c|c|c|}
\hline Acid formulas & Rock number & Test time $(\min )$ & Reaction temperature $\left({ }^{\circ} \mathrm{C}\right)$ \\
\hline \multirow[t]{8}{*}{$15 \% \mathrm{HCl}$} & $\mathrm{A} 1$ & 10 & 90 \\
\hline & $\mathrm{A} 2$ & 20 & \\
\hline & A3 & 30 & \\
\hline & A4 & 40 & \\
\hline & A5 & 50 & \\
\hline & A6 & 60 & \\
\hline & A7 & 120 & \\
\hline & A8 & 180 & \\
\hline \multirow[t]{8}{*}{$15 \% \mathrm{HCl}+\mathrm{EA}\left(\omega_{\mathrm{EA}}=5 \%\right)$} & B1 & 10 & \\
\hline & B2 & 20 & \\
\hline & B3 & 30 & \\
\hline & B4 & 40 & \\
\hline & B5 & 50 & \\
\hline & B6 & 60 & \\
\hline & B7 & 120 & \\
\hline & B8 & 180 & \\
\hline
\end{tabular}

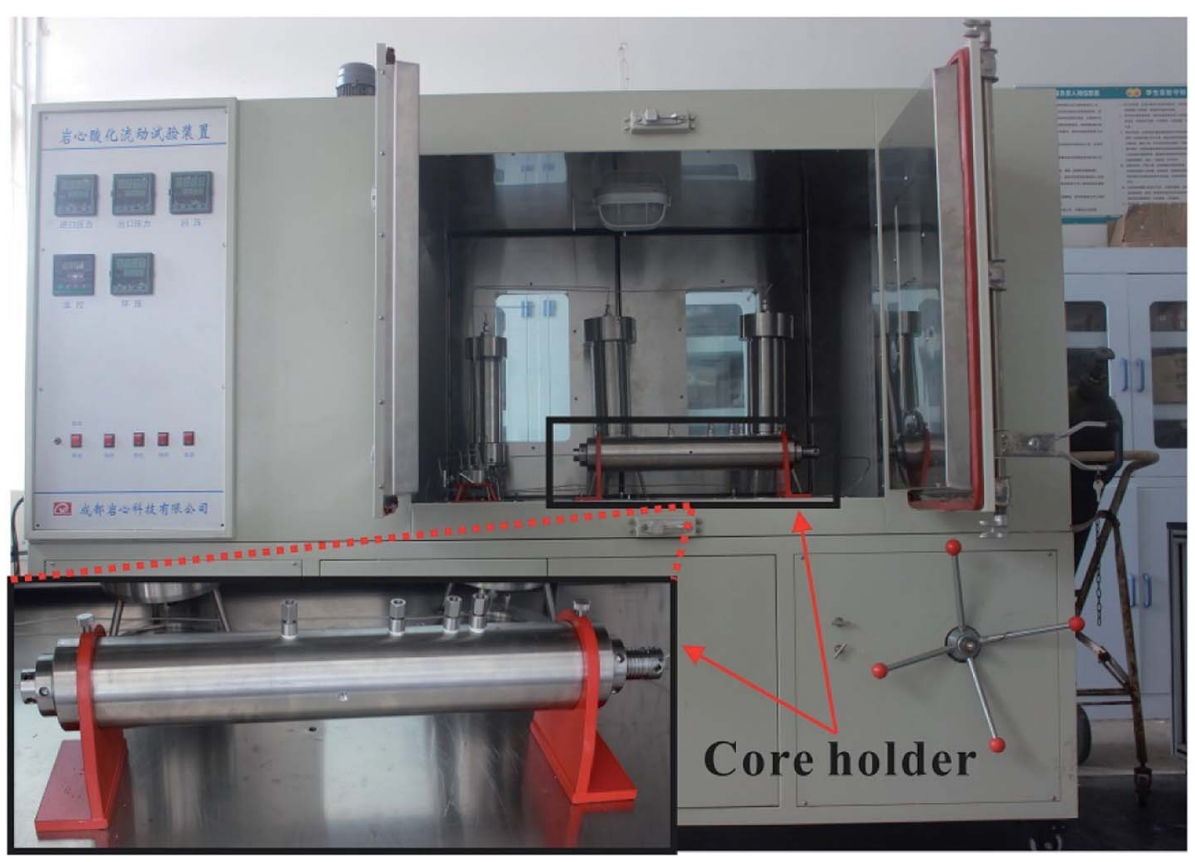

Fig. 4 The acid-etched fracture conductivity equipment and the core holder. 
Table 2 Acid compositions during the conductivity tests

\begin{tabular}{|c|c|c|c|c|}
\hline Number & 1 & 2 & 3 & 4 \\
\hline Acid composition & $5 \% \mathrm{HCl}$ & $10 \% \mathrm{HCl}$ & $15 \% \mathrm{HCl}$ & $20 \% \mathrm{HCl}$ \\
\hline Number & 5 & 6 & 7 & 8 \\
\hline Acid composition & $\begin{array}{l}5 \% \mathrm{HCl}+\mathrm{EA} \\
\omega_{\mathrm{CCRSA}}=5 \%\end{array}$ & $\begin{array}{l}10 \% \mathrm{HCl}+\mathrm{EA} \\
\omega_{\mathrm{CCRSA}}=5 \%\end{array}$ & $\begin{array}{l}15 \% \mathrm{HCl}+\mathrm{EA} \\
\omega_{\mathrm{CCRSA}}=5 \%\end{array}$ & $\begin{array}{l}20 \% \mathrm{HCl}+\mathrm{EA} \\
\omega_{\mathrm{CCRSA}}=5 \%\end{array}$ \\
\hline
\end{tabular}

was turned on and the temperature was set to $120^{\circ} \mathrm{C}$. (5) After the acid tank and core holder were heated to $120^{\circ} \mathrm{C}$, the acid etching step was performed with an acid injection displacement of $0.5 \mathrm{~L} \mathrm{~min}^{-1}$ and an acid injection time of $30 \mathrm{~min}$. The outlet residual acid was neutralized by $\mathrm{NaOH}$ solution. (6) After exposure, the rock was taken out and the residual acid on the rock plate surface was washed away. A 3D scan of the surface was performed to obtain the surface morphology of the rock plates after acid etching. (7) After laser scanning, the eight pairs of rock plates were put into the core holder again to test the injection pressure difference and discharge under closing pressures of 5, 10, 20,30,40, and $50 \mathrm{MPa}$ (that is, the normal stress of each pair of rock plates). The conductivity was calculated using eqn (3).

$$
k_{\mathrm{f}} w_{\mathrm{f}}=1.67 \times 10^{-3} \frac{Q \mu L}{h \Delta P}
$$

where $k_{\mathrm{f}} w_{\mathrm{f}}$ refers to the acid-etched fracture conductivity, $\mu \mathrm{m}^{2} \mathrm{~cm} ; Q$ refers to the acid injection displacement, $\mathrm{mL} \mathrm{min}^{-1}$; $\mu$ refers to the acid viscosity, mPa s; $L$ refers to the rock plate length, $\mathrm{cm} ; h$ refers to the rock plate width, $\mathrm{cm}$; and $\Delta P$ refers to the pressure difference between the ends of the rock plate.

\section{Results and discussion}

\subsection{ESEM and energy spectrum analysis of the EA}

The ESEM test results for the EA are summarized in Fig. 5. EA particles are shown in Fig. 5a. In the upper left corner of the photograph, a number of small holes with different sizes between 10 and $30 \mu \mathrm{m}$ in diameter are evident on the surfaces of the EA particles. These holes resulted from uneven spraying during encapsulation. Most of the EA particles had dense, nonpermeable encapsulation layers on the surface and hence the HTRCM achieved effective encapsulation for the SHA. The surface morphology of the EA, magnified 10000 times, is shown in Fig. 5b. As can be observed from Fig. 5b, the large number of fibrous polymer materials further confirmed that the surface of the EA was successfully encapsulated by the HTRCM.

The energy spectrum analysis curve of the EA is shown in Fig. 6. From the analysis results, the EA mainly consisted of $\mathrm{C}, \mathrm{N}, \mathrm{O}, \mathrm{Cl}$ and other elements. The $\mathrm{C}, \mathrm{N}$, and $\mathrm{O}$ shown in the

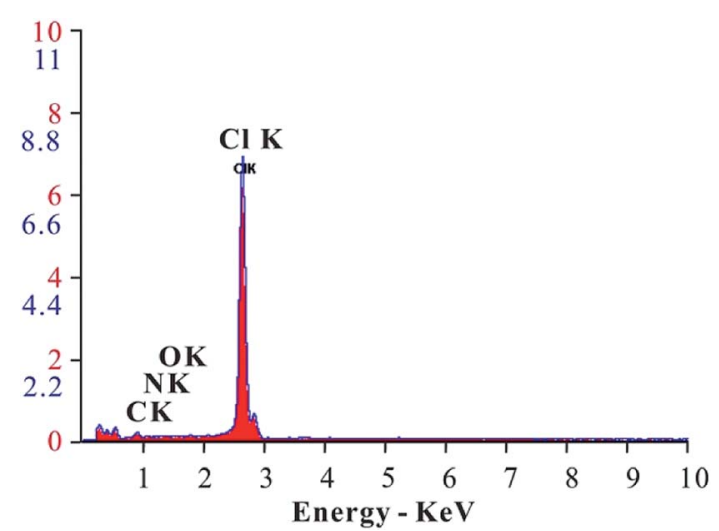

Fig. 6 Energy spectrum analysis plot for the EA.
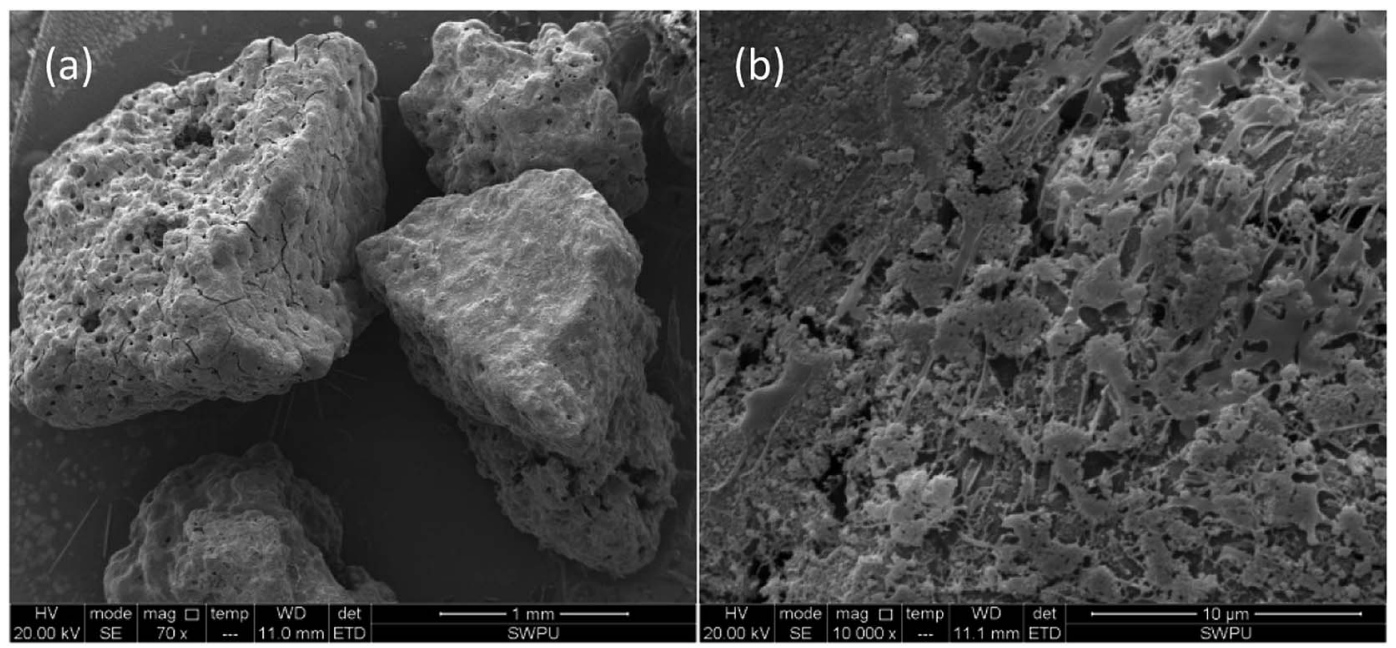

Fig. 5 Microscopic appearance of the EA ((a) magnified 70 times; (b) magnified 10000 times). 


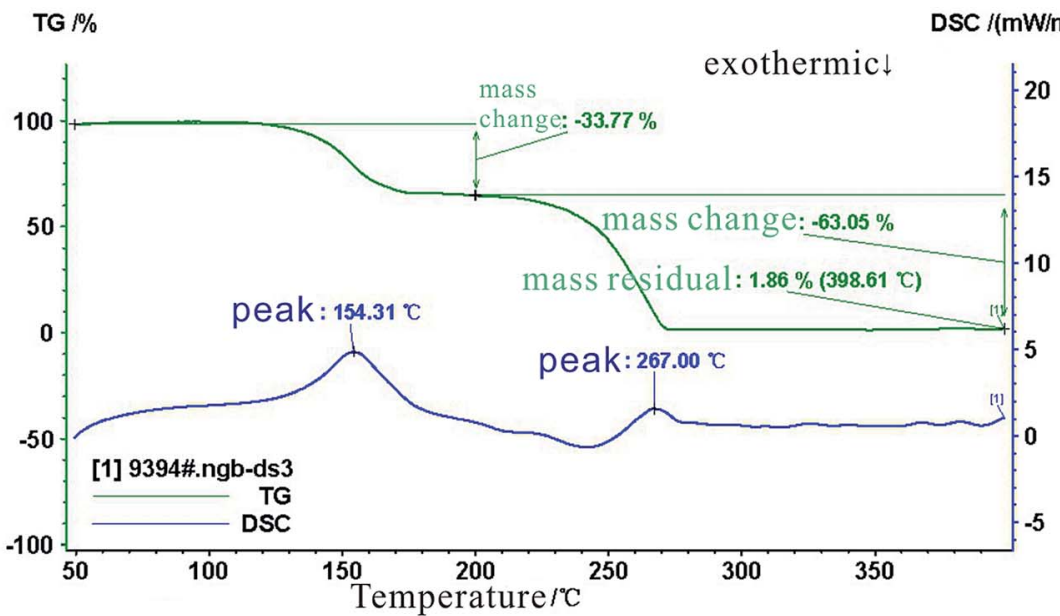

Fig. 7 Change of solid acid mass with temperature.

energy spectrum analysis results were from the HTRCM and the Cl was from the SHA. It was confirmed that the SHA was effectively encapsulated by the HTRCM. As energy spectrum analysis cannot test the $\mathrm{H}$ element content, it cannot be simply inferred that the EA did not contain the element $\mathrm{H}$. Instead, it was inferred that the $\mathrm{H}$ element content was not too low from the raw material synthesizing the HTRCM and the elemental composition of encapsulated SHA.

\subsection{Thermogravimetric analysis of the SHA}

The results of the thermogravimetric (TG) analysis and from the differential scanning calorimeter (DSC) tests are shown in Fig. 7. These results show that the mass of the SHA remained unchanged when the temperature was increased from $45{ }^{\circ} \mathrm{C}$ to $135{ }^{\circ} \mathrm{C}$. The SHA began to decompose and the mass decreased when the temperature exceeded $135{ }^{\circ} \mathrm{C}$. The SHA had decomposed completely at $267^{\circ} \mathrm{C}$. From the DSC results, when the temperature increased to $154.31{ }^{\circ} \mathrm{C}$, an exothermic peak appeared, the SHA decomposition rate decreased, and the residual mass tended to be stable. At $267^{\circ} \mathrm{C}$, a peak appeared in the DSC curve again, and the SHA almost decomposed completely. These results show that SHA retained its thermal stability below $135{ }^{\circ} \mathrm{C}$.

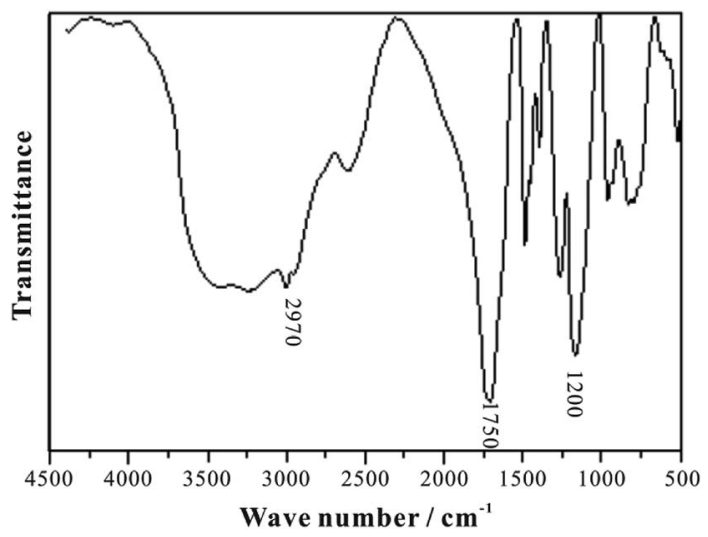

Fig. 8 The infrared spectrum of HTRCM.

\subsection{FTIR results}

The infrared spectrum of HTRCM is shown in Fig. 8. The amide group $\mathrm{N}-\mathrm{H}$ absorption peak and the carboxylic group $\mathrm{O}-\mathrm{H}$ absorption peak appeared at about $3200-3500 \mathrm{~cm}^{-1}$, the absorption peak of the main chain structure $-\mathrm{CH}_{2}$ - appeared at about $2970 \mathrm{~cm}^{-1}$, the absorption peak of $\mathrm{C}=\mathrm{O}$ in $\mathrm{AL}$ and $\mathrm{AC}$

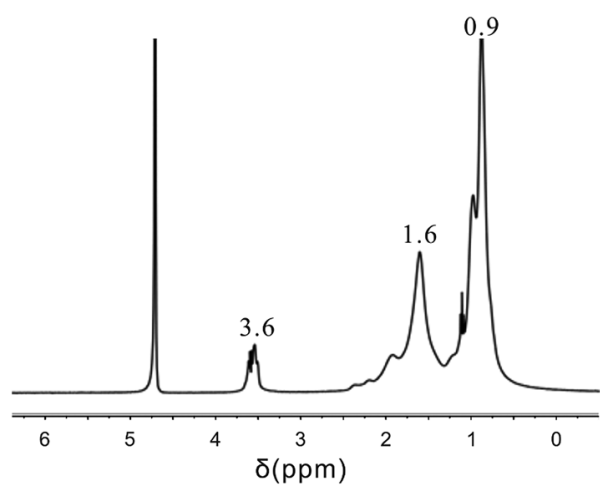

Fig. $9{ }^{1} \mathrm{H}$ NMR spectrum.

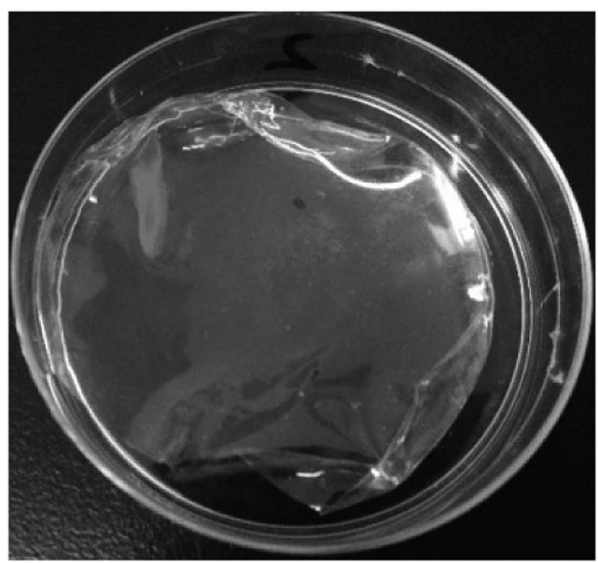

Fig. 10 The appearance of the HTRCM film. 


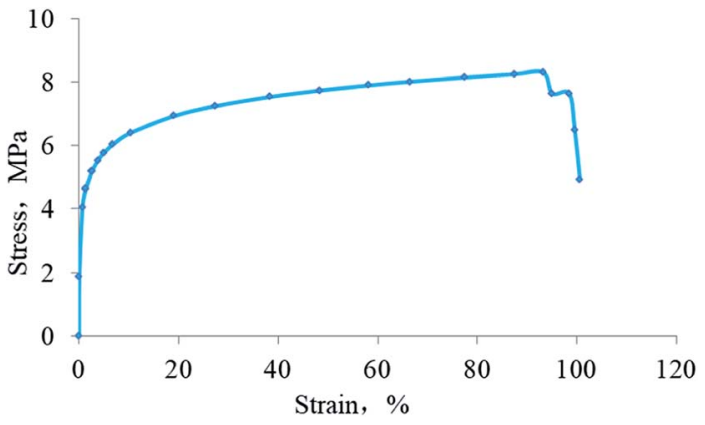

Fig. 11 Stress-strain curve of HTRCM.

appeared at about $1750 \mathrm{~cm}^{-1}$, and the absorption peak of C-O-C in AAP appeared at about $1200 \mathrm{~cm}^{-1}$. Hence, it can be inferred that AL, AC, DL, and AAP all linked to HTRCM successfully.

\subsection{NMR results}

It can be seen from the ${ }^{1} \mathrm{H}$ NMR spectrum given in Fig. 9 that the NMR peak of $\mathrm{H}$ atoms from the polyether in AAP appeared at about $3.6 \mathrm{ppm}$, the NMR peak of $\mathrm{H}$ atoms from the $-\mathrm{CH}_{2}-$ structure in the DL appeared at about $1.6 \mathrm{ppm}$, and the NMR peak of $\mathrm{H}$ atoms from the carboxylic ester in $\mathrm{AC}$ and the alkyl in AAP appeared at about $0.9 \mathrm{ppm}$. The HTRCM contained the structures from the AL, AC, PL, and AAP; that is, the HTRCM exhibited the designed target structure.

\subsection{Mechanical performance of the HTRCM}

Fig. 10 demonstrates the appearance of the HTRCM after film formation. The film made by HTRCM was complete on the surface and had a certain toughness.

The stress-strain curve of the HTRCM is shown in Fig. 11 . The maximum tensile stress of the HTRCM was $8.31 \mathrm{MPa}$ and the strain reached $91 \%$. The test results showed that HTRCM not only had a certain strength but also had suitable deformation characteristics and impact resistance.

\subsection{Dissolution of the HTRCM}

The dissolution behavior of the HTRCM in different solvents at room temperature is illustrated in Fig. 12. As can be seen from the figure, HTRCM did not dissolve in EAC or DE but had good solubility in $\mathrm{AE}$, deionized water, and $\mathrm{NaOH}$ solution $\left(0.01 \mathrm{~g} \mathrm{~mL}^{-1}\right)$. The test results showed that the HTRCM will dissolve completely in alkaline and neutral solvents, releasing the internal encapsulated SHA.

The dissolution of the HTRCM in the acid and alkali solutions at higher temperature $\left(135^{\circ} \mathrm{C}\right)$ is illustrated in Fig. 13. It can be observed from the test results that the HTRCM hardly dissolved in the concentrated hydrochloric acid and retained a very obvious faceted surface structure but dissolved completely in the sodium hydroxide solution. The results show that the HTRCM is insoluble in high-concentration acid solution (37\%) and can be used to encapsulate SHA. It will release the encapsulated SHA with the consumption of $\mathrm{H}^{+}$ions.
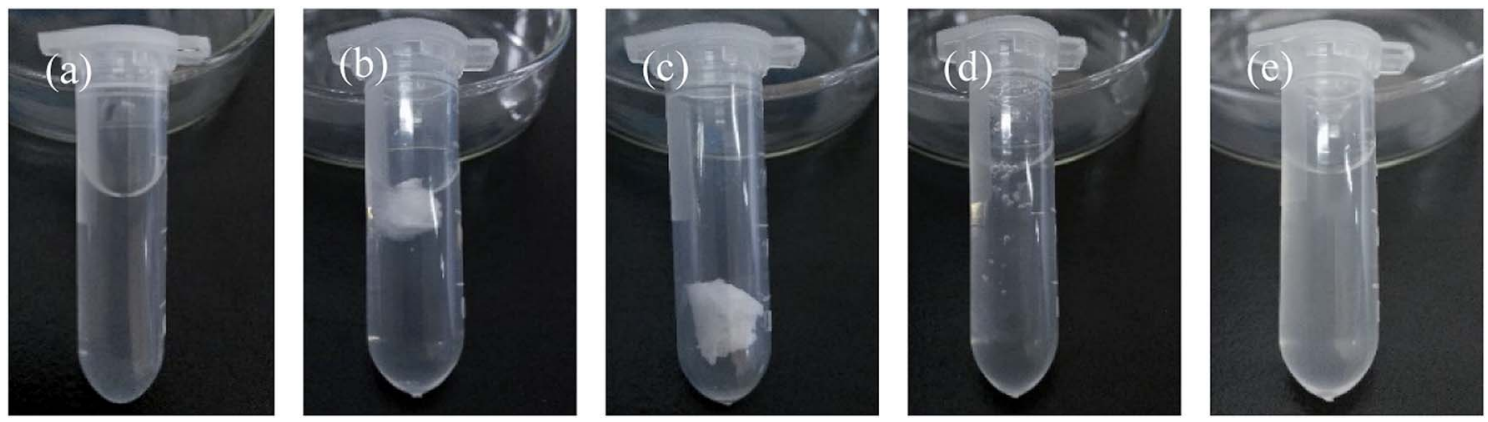

Fig. 12 Dissolution of the HTRCM in different solvents (the solubility is determined using eqn (1) where $R>95 \%$ is insoluble, $20 \%<R \leq 95 \%$ is partially dissolved, $5 \%<R \leq 20 \%$ is easily soluble, and $0 \leq R \leq 5 \%$ is highly soluble). (a) AE, (b) EAC, (c) DE, (d) deionized water, and (e) $0.01 \mathrm{~g} \mathrm{~mL}{ }^{-1}$ $\mathrm{NaOH}$ solution.
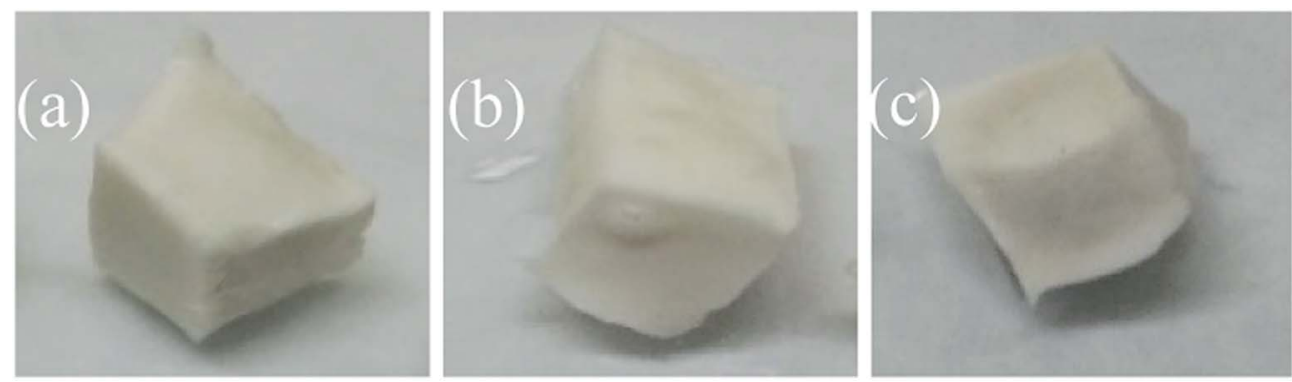

Fig. 13 Dissolution of the HTRCM in concentrated hydrochloric acid and sodium hydroxide solution at $135^{\circ} \mathrm{C}$. (a) Before the dissolution test in concentrated $\mathrm{HCl}$ solution. (b) After the dissolution test in concentrated $\mathrm{HCl}$ solution. (c) Before the dissolution test in $\mathrm{NaOH}$ solution. 


\subsection{Effect of the $\mathbf{H}^{+}$ion concentration in the carrying fluid on the release of the $\mathrm{EA}$}

The effects of different $\mathrm{H}^{+}$concentrations in the carrying fluid on the residual rate of EA are illustrated in Fig. 14. When the $\mathrm{HCl}$ concentration in the carrying liquid fell from $30 \%$ to $14 \%$, the mass residual rate of the EA was still around $100 \%$ after 1 hour at $135{ }^{\circ} \mathrm{C}$, which indicated that the SHA had not been released. When the $\mathrm{H}^{+}$concentration of the carrying fluid decreased from $14 \%$ to $8 \%$, the residual mass rate of the EA decreased slowly. However, when the $\mathrm{H}^{+}$concentration was below $8 \%$, the residual mass rate of the EA decreased quickly. Compared with the existing encapsulated acids, ${ }^{18-22}$ the encapsulating material in this paper is completely dissolved in neutral solution, avoiding damage to the reservoir by the residue.

As observed, the acid concentration had a great effect on the SHA release. The $\mathrm{H}^{+}$ion concentration was high near the wellbore and the structure of the HTRCM was complete, which effectively isolated the SHA. However, when the EA had been transported to the far end zone of the artificial fracture, the $\mathrm{H}^{+}$ ion concentration in the carrying liquid is gradually consumed, resulting in a decrease in the $\mathrm{H}^{+}$ion concentration. As the structure of the HTRCM is destroyed, releasing SHA, ionization produces new $\mathrm{H}^{+}$ions, which restores the $\mathrm{H}^{+}$ion concentration of the carrying fluid, resulting in a decrease in the release rate of the SHA. If the concentration of $\mathrm{H}^{+}$ions decreases, the EA releases the SHA to restore the $\mathrm{H}^{+}$ion concentration. Nevertheless, the acid-rock reaction consumes the $\mathrm{H}^{+}$ions, resulting in the decrease of the $\mathrm{H}^{+}$ion concentration. The above cyclical process increases the etching length of acid fracturing, as shown in Fig. 1.

\subsection{Effects of temperature on EA release}

The effect of temperature on the EA release rate is shown in Fig. 15. It demonstrates that the residual mass rate of the EA decreased with the increase of temperature when the hydrochloric acid concentration was $11-14 \%$. The degree of decrease in the residual rate was inversely proportional to the hydrochloric acid concentration. The mass residual rate of the

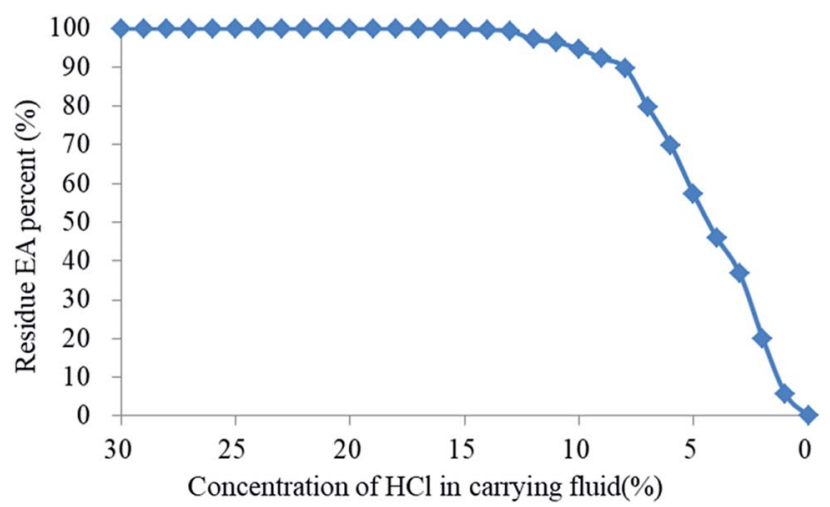

Fig. 14 Effect of different $\mathrm{H}^{+}$concentrations in the carrying fluid on the residual rate of the EA.

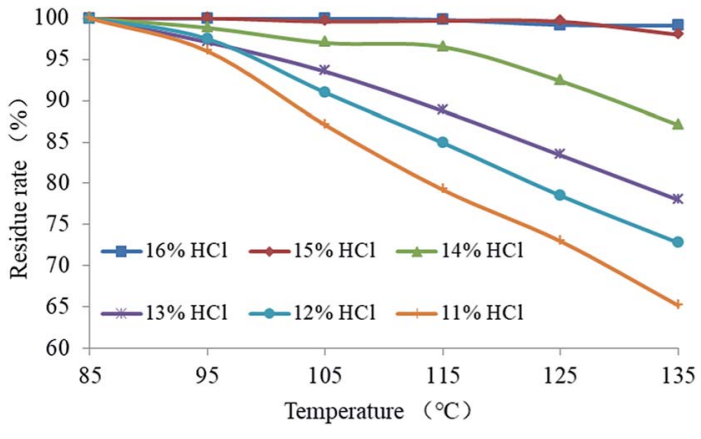

Fig. 15 Effect of temperature on EA release.

EA in $11 \%$ hydrochloric acid decreased to $65 \%$ at $135^{\circ} \mathrm{C}$. When the hydrochloric acid concentration was $15 \%$ or more, the mass residual rate of the EA was almost unchanged with the increase of temperature. As a result, the critical hydrochloric acid concentration of the EA release was $15 \%$. The results demonstrated that the HTRCM has good acid-resistance performance in $15 \% \mathrm{HCl}$ solution at $135{ }^{\circ} \mathrm{C}$ and that the EA still has good acid-resistance performance even in $11 \% \mathrm{HCl}$ solution at $95{ }^{\circ} \mathrm{C}$, which indicates that the critical release temperature of the EA is $95{ }^{\circ} \mathrm{C}$ (hydrochloric acid concentration $\leq 14 \%$ ).

The temperature in the hydraulic fractures is shown in Fig. 16. As can be observed, the temperature was lower near the well and gradually increased along the fracture. ${ }^{29}$ The temperature at the leading fracture edge was equal to the initial reservoir temperature. According to the EA release under different temperature conditions shown in Fig. 15, the fracture temperature field can be used to further control the release of the EA. Owing to the lower temperature near the well, the SHA was hardly released. When the EA migrated to the middle area of the hydraulic fracture, the reaction between the acid and the rock caused a decrease in the $\mathrm{H}^{+}$ ion concentration in the carrying liquid. As a result, the EA began to release the SHA, which entered the cycle process shown in Fig. 1. Because of the lower temperature, the SHA did not release completely, which allowed the EA to migrate to the far end of the fractures and improved the etching length.

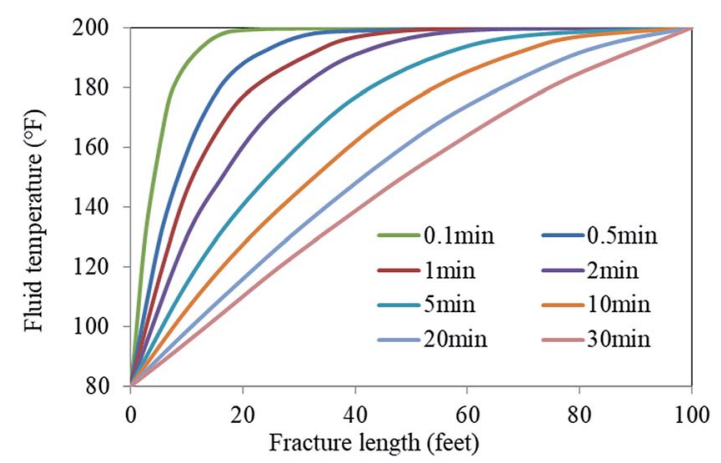

Fig. 16 Temperature distribution from the well along the fracture. ${ }^{29}$ 
Table 3 Test results of the effective content

\begin{tabular}{|c|c|c|c|c|c|}
\hline Group & $\begin{array}{l}\text { Mass of } \mathrm{NaOH} \\
M_{1}(\mathrm{~g})\end{array}$ & $\begin{array}{l}\text { Hydrochloric acid concentration, } \\
c_{1}\left(\mathrm{~mol} \mathrm{~L}^{-1}\right)\end{array}$ & $\begin{array}{l}\text { Hydrochloric acid } \\
\text { volume of titration SHA, } V_{1}(\mathrm{~mL})\end{array}$ & $\begin{array}{l}\text { Hydrochloric acid } \\
\text { volume of titration EA, } V_{2}(\mathrm{~mL})\end{array}$ & $\begin{array}{l}\text { SHA content, } \\
P_{\text {SHA }}\end{array}$ \\
\hline 1 & 2.501 & 0.25 & 32.45 & 20.21 & $84.67 \%$ \\
\hline 3 & 2.501 & & 32.39 & 20.43 & $84.98 \%$ \\
\hline
\end{tabular}

\subsection{The effective content of the EA}

Test results for the effective content of the SHA test and the SHA content in the EA as calculated by eqn (2) are summarized in Table 3. As can be observed, the mass content of SHA in the EA was nearly $85 \%$, and encapsulating material accounted for about $15 \%$. The mass content of SHA was high, which enabled it to achieve better etching effects.

\subsection{Etching performance of the EA}

The appearance of the rock samples before and after etching by $\mathrm{HCl}$ and $\mathrm{HCl}+\mathrm{EA}$ is shown in Fig. 17 and 18, respectively. The rock block size and acid concentration before and after etching are presented in Table 4. As shown in Fig. 17 and 18, the surface of all rock block was smoother after etching than was the case before etching, but the extent of etching was not equal at different positions on the rock surface and the rock samples had a trapezoidal shape after etching.

From the etching test results shown in Table 4, the degree of rock block consumption increased with the increase of the etching time in $\mathrm{HCl}$ solution. Nevertheless, when the reaction time exceeded $60 \mathrm{~min}$, the consumed rock mass tended to be stable as the hydrochloric acid concentration had decreased, resulting in an inability to consume more rock. When $\mathrm{HCl}+\mathrm{EA}$ solution was used, the EA could release SHA to restore the $\mathrm{H}^{+}$ ion concentration after $\mathrm{H}^{+}$consumption. Thus, more rock was consumed. As shown in Fig. 19, when the etching time was less than $60 \mathrm{~min}$, the rock mass consumption increased with an associated rapid decrease in acid concentration using $\mathrm{HCl}+\mathrm{EA}$. When the etching time exceeded $60 \mathrm{~min}$, the residual acid concentration was stable at nearly $8 \%$ and the quantity of rock consumption continued to increase.

The results of the acid-rock consumption tests further confirmed the differences in the dynamic change in $\mathrm{H}^{+}$ion concentration between the two acid mixtures. The concentration of $\mathrm{H}^{+}$ions in the carrying fluid decreased owing to the chemical process between the rock and the acid. The HTRCM structure was destroyed owing to the dual control by $\mathrm{H}^{+}$ions and temperature, releasing the encapsulated SHA to restore the $\mathrm{H}^{+}$ion concentration in the fluid and maintain the concentration of the acid. The $\mathrm{H}^{+}$ion concentration change was in a state of dynamic equilibrium, as shown in Fig. 1.

\subsection{Acid-etched fracture conductivity for the EA}

The degree to which the acid etching capability persists along the fracture path under different hydrochloric acid concentrations and for hydrochloric acid mixed with EA is shown in
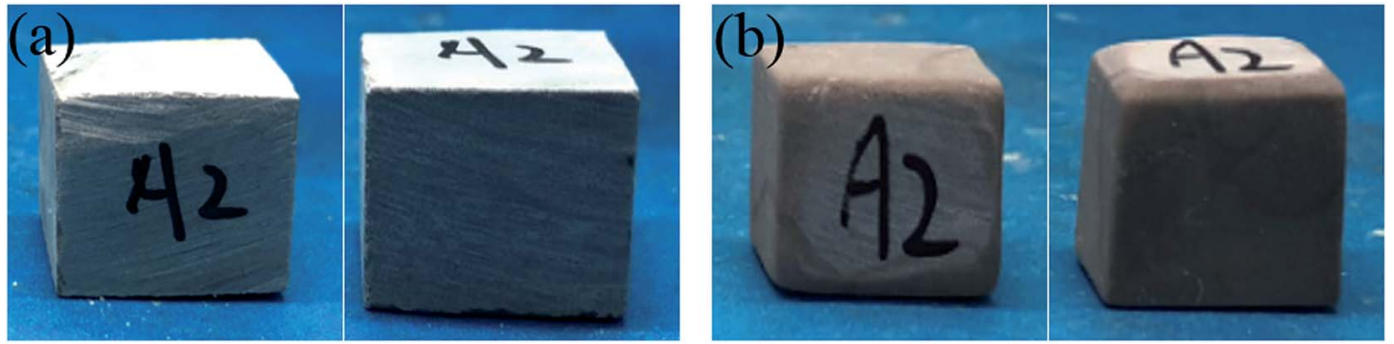

Fig. 17 A2 rock appearance. (a) Rock sample before etching in $\mathrm{HCl}$ and (b) rock sample after etching in $\mathrm{HCl}$.
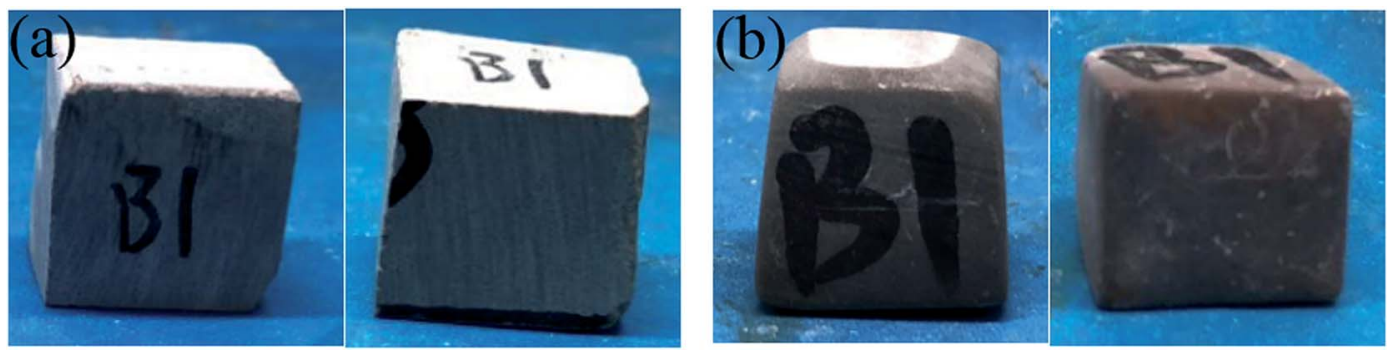

Fig. 18 B1 rock appearance. (a) Rock sample before etching in $\mathrm{HCl}+\mathrm{EA}$ and (b) rock sample after etching in $\mathrm{HCl}+\mathrm{EA}$. 
Table 4 Rock mass and acid concentration before and after etching

\begin{tabular}{|c|c|c|c|c|c|}
\hline Core number & \multicolumn{2}{|l|}{ Before etching } & \multicolumn{2}{|l|}{ After etching } & Rock consumption mass (g) \\
\hline $\mathrm{A} 2$ & 10.16 & 15 & 7.98 & 12.84 & 2.17 \\
\hline A3 & 10.34 & 15 & 7.67 & 12.02 & 2.67 \\
\hline A4 & 10.51 & 15 & 6.82 & 11.51 & 3.69 \\
\hline A7 & 10.37 & 15 & 4.85 & 6.42 & 5.52 \\
\hline A8 & 9.83 & 15 & 3.92 & 4.21 & 5.91 \\
\hline B1 & 9.02 & 15 & 7.43 & 15.25 & 1.59 \\
\hline B2 & 9.20 & 15 & 6.29 & 14.70 & 2.91 \\
\hline B3 & 11.97 & 15 & 7.71 & 13.89 & 4.26 \\
\hline B4 & 8.32 & 15 & 3.56 & 13.24 & 4.76 \\
\hline
\end{tabular}

Fig. 20. At higher closing pressures, the conductivity of different acid mixtures was decreased. Using different concentrations of hydrochloric acid for etching, the measured conductivity first increased and then decreased. This was because when the hydrochloric acid concentration was lower than $15 \%$, the amount of rock mineral consumed by the acid increased and therefore the ability of the acid to permeate along the fracture faces increased with the increase in acid concentration. However, when the acid concentration exceeded $15 \%$, excessive etching of the rock took place, causing the fracture faces to close, which resulted in a decrease in the capability of the injected acid to permeate along the fracture faces in the rock strata. It can be inferred from Fig. 14 that the EA completely released its SHA in $5 \%$ and $10 \% \mathrm{HCl}$ solution, thereby maintaining the $\mathrm{H}^{+}$ion concentration in the solution, and therefore the conductivity when using $(5 \% \mathrm{HCl}+5 \% \mathrm{EA})$ was higher than that when using only $5 \% \mathrm{HCl}$, and was similar to the performance when using $10 \% \mathrm{HCl}$. The conductivity when using $(10 \% \mathrm{HCl}+5 \% \mathrm{EA})$ was much higher than that

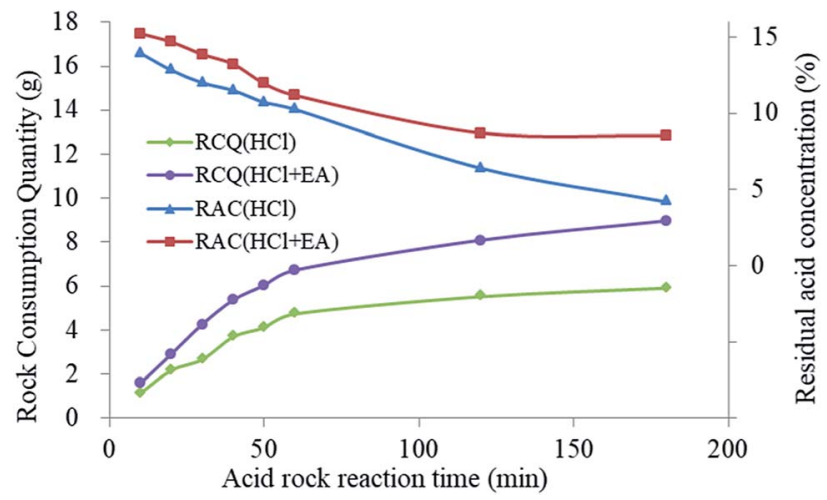

Fig. 19 Rock consumption quantity (RCQ) and residual acid concentration (RAC) for different reaction times. when using straight $10 \% \mathrm{HCl}$. In addition, it can be inferred from the results shown in Fig. 20 that the EA released hardly any SHA in $15 \% \mathrm{HCl}$. However, once a proportion of the $\mathrm{H}^{+}$ ions had been consumed, that promoted the EA to release SHA to restore the $\mathrm{H}^{+}$ion concentration in the solution. Excessive etching was evident when using $(15 \% \mathrm{HCl}+5 \%$ EA), which resulted in a lower acid persistence than when using $15 \% \mathrm{HCl}$. Compared with $15 \% \mathrm{HCl}$, more $\mathrm{H}^{+}$ions must be consumed from $20 \% \mathrm{HCl}$ before the release of the SHA from the EA is triggered. During these tests, owing to the shorter cores employed, the amount of residual $\mathrm{H}^{+}$ions did not reach the critical release concentration for the EA. As the release of SHA from the EA was less, the conductivity using $20 \% \mathrm{HCl}$ was close to that using $20 \% \mathrm{HCl}+5 \% \mathrm{EA}$.

The findings of the tests for $10 \% \mathrm{HCl}$ and $10 \% \mathrm{HCl}+5 \% \mathrm{EA}$ conductivity are shown in Fig. 21 and 22 . Before etching (Fig. 21a and 22a), the sample surfaces were smooth without obvious grooves and the fracture width formed by the combination of the two rock plates was narrow (Fig. 21b and 22b).

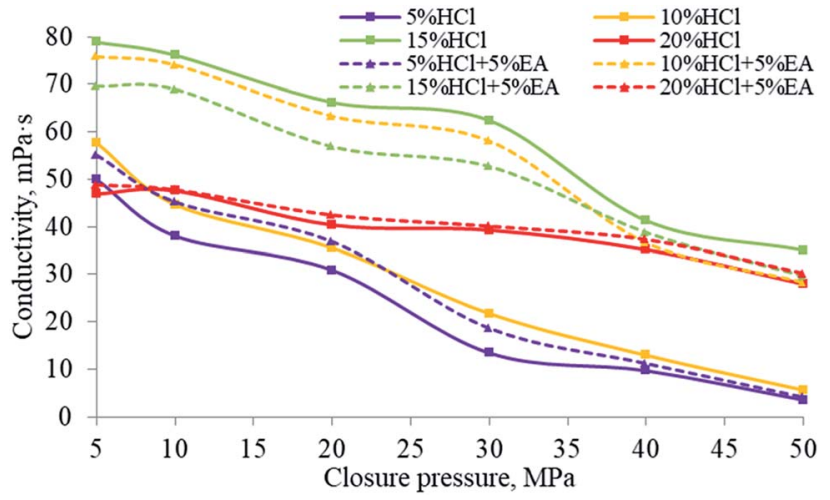

Fig. 20 Acid persistence for different hydrochloric acid concentrations and for hydrochloric acid mixed with the EA. 


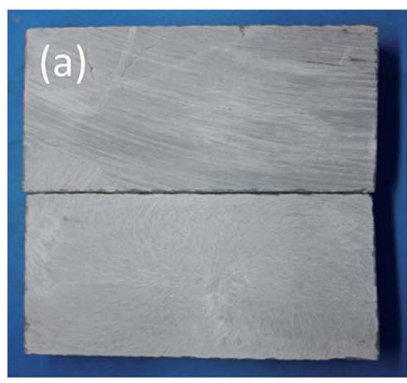

(e)

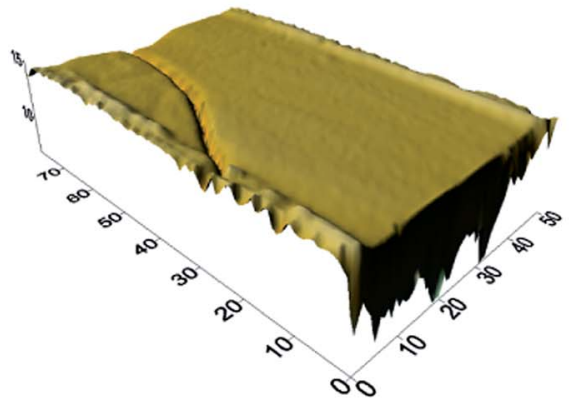

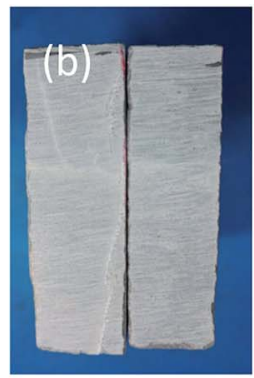

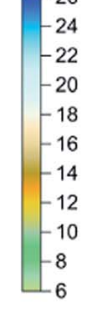

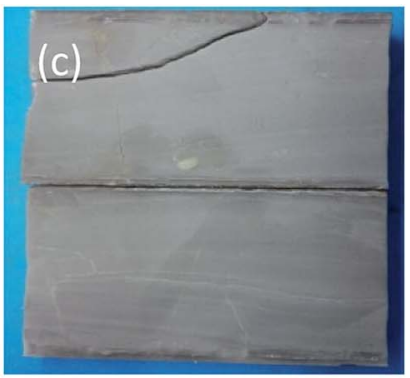

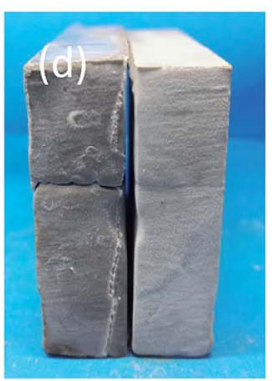

(f)

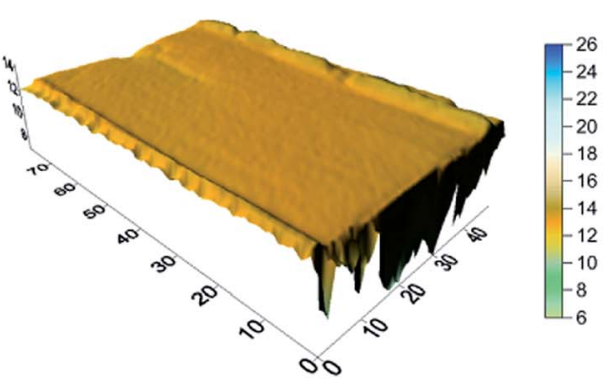

Fig. $2110 \% \mathrm{HCl}$ conductivity experimental results. (a) Morphology of fracture surface before acid etching; (b) morphology of fracture inlet before acid etching; (c) morphology of fracture surface after acid etching; (d) morphology of fracture inlet after acid etching; and (e and f) 3D scanning morphology of fracture surface after acid etching.

After acid etching the rock plate, the acid reacted with the cement in the rock plate, causing the rock plate to break (Fig. 21c and 22c). After etching (Fig. 21d and 22d), the fracture width formed by the combination of the two rock plates was significantly larger than that before the etching.
From the results of laser scanning analysis of the rock plates after etching (Fig. 21e, f and 22e, f), etching grooves appeared on the etched surfaces, which increased the fracture conductivity. However, compared with those produced by the $10 \% \mathrm{HCl}$, the etching grooves of $10 \% \mathrm{HCl}+5 \%$ EA were deeper and, as a consequence, the conductivity was higher.
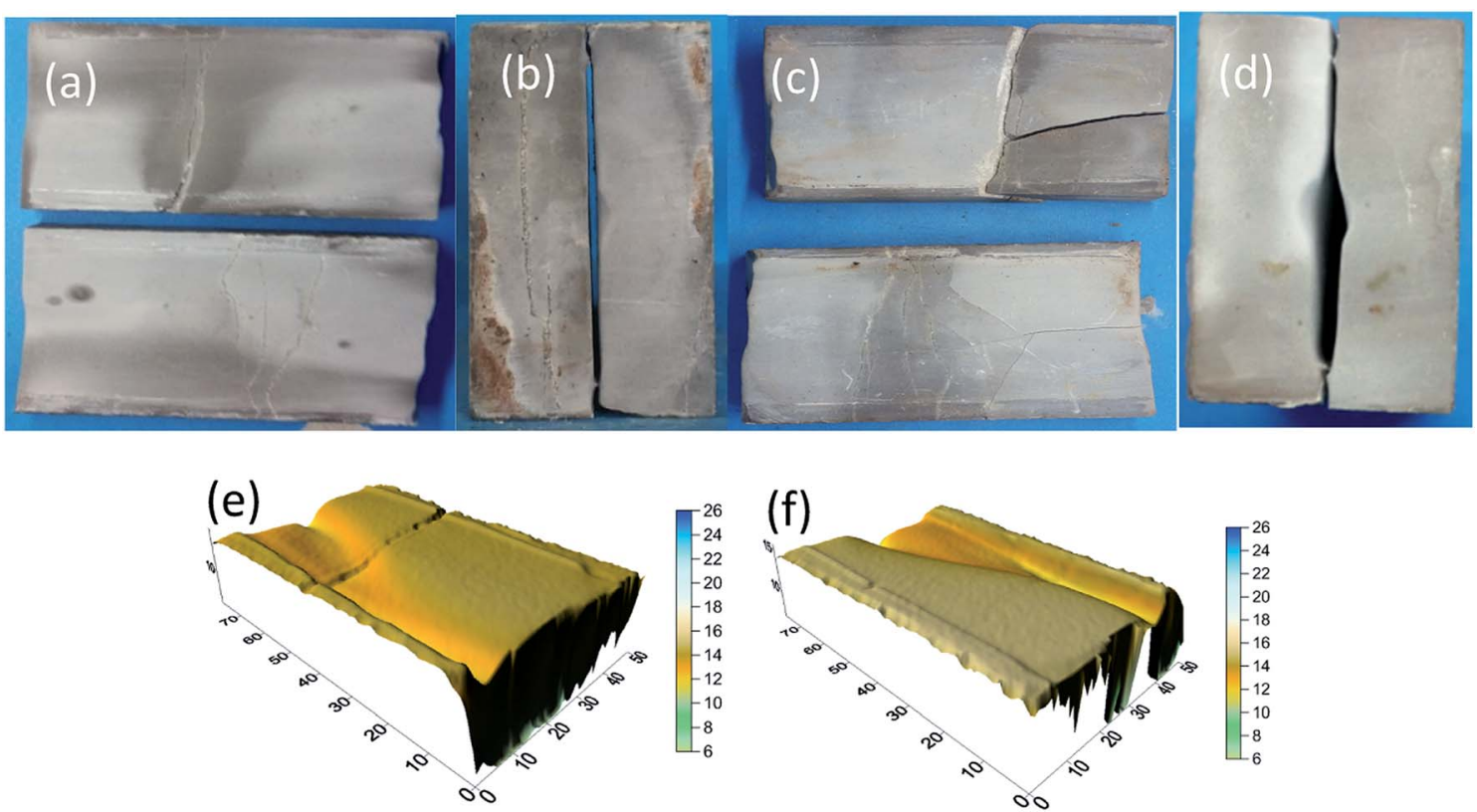

Fig. $2210 \% \mathrm{HCl}+5 \%$ EA conductivity experimental results. (a) Morphology of fracture surface before acid etching; (b) morphology of fracture inlet before acid etching; (c) morphology of fracture surface after acid etching; (d) morphology of fracture inlet after acid etching; and (e), (f) 3D scanning morphology of fracture surface after acid etching. 


\section{Conclusions}

In this study, a novel EA has been described that is comprehensively controlled by hydrogen ion concentration and temperature. The described procedures included the preparation of the solid acid SHA, the preparation of the encapsulation material HTRCM for controllable release, and the encapsulation of the solid acid.

ESEM and energy spectrum analysis confirmed that the surface of the EA was successfully encapsulated by the encapsulation material. Thermal stability tests conducted on the solid acid demonstrated that the solid acid can maintain its stability below $135{ }^{\circ} \mathrm{C}$. FTIR and NMR tests demonstrated that the encapsulation material achieved its intended functionality. Mechanical tests of the encapsulation material demonstrated that the material had good mechanical strength, strong impact resistance, and adequate abrasion resistance. Dissolution tests demonstrated that the encapsulation material had the required characteristics of acid resistance and good encapsulation performance. Experiments to investigate the release behavior, effective solid acid content, etching ability, and fracture conductivity demonstrated that the controlled release of the EA prepared using the encapsulation approach was highly effective in maintaining the acid concentration, its etching capability and the controllable release of $\mathrm{H}^{+}$ions.

Compared with existing encapsulated acids, the encapsulating material in this paper is completely dissolved in neutral solution, thus avoiding reservoir damage by the residue.

\section{Nomenclature}

$\begin{array}{ll}\text { EA } & \text { Encapsulated acid } \\ \text { ESEM } & \text { Environmental scanning electron microscope } \\ \text { TGA } & \text { Thermogravimetric analysis } \\ \text { FTIR } & \text { Fourier transform infrared spectroscopy } \\ \text { NMR } & \text { Nuclear magnetic resonance } \\ \text { HTRCM } & \text { H }^{+} \text {ion-temperature responsive coating material } \\ \text { SHA } & \text { Solid hydrochloric acid } \\ \text { AL } & \text { Acrylamide monomers } \\ \text { AC } & \text { tert-Butyl allyl carboxylate monomers } \\ \text { DL } & \text { Diallylamine monomers } \\ \text { AAP } & \text { Allyl alkyl polyether monomers } \\ \text { AE } & \text { Absolute ethanol } \\ \text { AP } & \text { Anion polyacrylamide } \\ \text { EAC } & \text { Ethyl acetate } \\ \text { DE } & \text { Dichloromethane }\end{array}$

\section{Conflicts of interest}

The authors declare no competing financial interest.

\section{Acknowledgements}

This work was supported by the National Natural Science Foundation of China (Grant No. 5197041731), the National
Science and Technology Major Projects (Grant No. 2016ZX05014, 2016ZX05052) and the Open Funding of State Key Laboratory of Oil and Gas Reservoir Geology and Exploitation (Southwest Petroleum University) (Grant No. PLN1214).

\section{References}

1 L. Sun, C. Zou, R. Zhu, Y. Zhang, S. Zhang, B. Zhang, G. Zhu and Z. Gao, Formation, distribution and potential of deep hydrocarbon resources in China, Pet. Explor. Dev., 2013, 40, 687-695.

2 H. Xue, Z. Huang, L. Zhao, H. Wang, B. Kang, P. Liu, F. Liu, Y. Cheng and J. Xin, Influence of acid-rock reaction heat and heat transmission on worm-holing in carbonate rock, J. Nat. Gas Sci. Eng., 2018, 50, 189-204.

3 N. Li, F. Zeng, J. Li, Q. Zhang, Y. Feng and P. Liu, Kinetic mechanics of the reactions between $\mathrm{HCl} / \mathrm{HF}$ acid mixtures and sandstone minerals, J. Nat. Gas Sci. Eng., 2016, 34, 792-802.

4 L. A. Kareem, Improved numerical simulation of wormhole propagation in carbonate core during acid stimulation, Brain, 2013, 130, 1596-1607.

5 A. Aminto and M. S. Olson, Four-compartment partition model of hazardous components in hydraulic fracturing fluid additives, J. Nat. Gas Sci. Eng., 2012, 7, 16-21.

6 J. Mou, K. Zheng, H. Chen and H. Zhang, A new method for measuring acid effective consumption time in acid fracturing, Adv. Mater. Res., 2014, 9, 1004-1005.

7 H. Quan, H. Li, Z. Huang, S. Dai and J. Jiang, Copolymer MCJS as a retarder of the acid-rock reaction speed for the stimulation of deep carbonate reservoirs, J. Appl. Polym. Sci., 2014, 132, 41471-41479.

8 R. C. Navarrete, B. A. Holms, S. B. McConnell and D. E. Linton, Laboratory, theoretical, and field studies of emulsified acid treatments in high-temperature carbonate formations, SPE Prod. Facil., 2000, 15, 96-106.

9 Y. Zhu, L. Zhao, P. Liu, P. Chen and W. Tao, Corrosion and Inhibition of P110 steel in $20 \% \mathrm{HCl}$ Solution by Mannich Base Inhibitor, Int. J. Electrochem. Sci., 2019, 14, 1331-1341.

$10 \mathrm{H}$. Zou, X. Wang and Y. Chen, Microscopic Evaluation of Emulsion Stability and Formula Optimization for Emulsified Acid, Presented at the 2nd International Conference on Green Communications and Networks, Berlin \& Heidelberg, Germany, Sep 29 to Oct 2, 2012.

11 S. Siddiqui, H. A. Nasr El Din and A. A. Khamees, Wormhole initiation and propagation of emulsified acid in carbonate cores using computerized tomography, J. Pet. Sci. Eng., 2006, 54(3), 93-111.

12 M. Alkhaldi, Reaction of citric acid with calcite, Chem. Eng. Sci., 2007, 62, 5880-5896.

13 V. Marcon, C. Joseph, K. E. Carter, S. W. Hedges, C. L. Lopano, G. D. Guthrie and A. Hakala, Experimental insights into geochemical changes in hydraulically fractured marcellus shale, Appl. Geochem., 2017, 76, 36-50.

14 A. I. Rabie, Reaction of calcite and dolomite with in situ gelled acids, organic acids, and environmentally friendly chelating agent, Texas A\&M University, 2012. 
15 L. Zhao, Y. Zhu, P. Liu, J. Zhang, Y. Liu, L. Qiao and Y. Yan, Corrosion and inhibition of $\mathrm{N} 80$ steel in $5 \% \mathrm{HCl}$ solution by SA1-3, Anti-Corros. Methods Mater., 2017, 64(6), 634-643.

16 Y. Zhu, L. Zhao, P. Liu and M. Yang, Subsection corrosion inhibition of acidic-oxidized polymer degradant in offshore oil field, Anti-Corros. Methods Mater., 2018, 65(5), 451-457.

17 K. Haruna, I. B. Obot, N. K. Ankah, A. A. Sorour and T. A. Saleh, Gelatin: a green corrosion inhibitor for carbon steel in oil well acidizing environment, J. Mol. Liq., 2018, 264, 515-525.

18 L. M. Johnson, S. D. Shepherd, G. D. Rothrock, A. J. Cairns and G. A. Almuntasheri, Core-Shell Systems for Delayed Delivery of Concentrated Mineral Acid, Presented at the SPE International Symposium on Oilfield Chemistry, Texas, USA, Apr 13, 2015.

19 L. Zhao, X. Liu, P. Liu, J. Li and X. Liu, Acid-frac technique with solid acid-new acid frac technique for carbonate reservoirs, Nat. Gas Ind., 2004, 24, 96-98.

20 M. E. Blauch, A. Cheng, K. Rispler and A. Khallad Novel Carbonate Well Production Enhancement Application for Encapsulated Acid Technology: First-Use Case History, Presented at the SPE Technical Conference \& Exhibition, Denver, Colorado, USA, Jan 1, 2003.

21 B. Gerardo, B. George and B. Marten, Acid fracturing with encapsulated citric acid, Presented at the SPE International Symposium and Exhibition on Formation Damage Control, Lafayette, Louisiana, USA, Jan 1, 2004.
22 M. Blauch and G. Funkhouser, Encapsulated acid improves facture results, Offshore, 2002, 235, 60-63.

23 L. Zhifeng, Z. Nanlin, Z. Liqiang, L. Hongtao, L. Pandeng and L. Ju, Innovative Encapsulating Acid with Release Dually Controlled by the Concentration of Hydrogen Ions and Temperature, Energy Fuels, 2019, 33(6), 4976-4985.

24 N. Li, F. Zeng, J. Li, Q. Zhang, Y. Feng and P. Liu, Kinetic mechanics of the reactions between $\mathrm{HCl} / \mathrm{HF}$ acid mixtures and sandstone minerals, J. Nat. Gas Sci. Eng., 2016, 34, 792-802.

25 L. I. Yang, K. Zhijiang, X. Zhaojie, Z. Songqing, C. P. Amp and C. Corporation, Theories and practices of carbonate reservoirs development in China, Pet. Explor. Dev., 2018, 45, 152-162.

26 J. Y. Mou, K. X. Zheng, H. J. Chen and H. Zhang, A new method for measuring acid effective consumption time in acid fracturing, Adv. Mater. Res., 2014, 9, 1004-1005.

27 E. Asadollahpour, A. Baghbanan and H. Hashemolhosseini, The etching and hydraulic conductivity of acidized rough fractures, J. Pet. Sci. Eng., 2018, 166, 704-717.

28 M. R. Akbari, M. J. Ameri and M. Pournik, Study of the Effect of Rock Type and Treatment Parameter on Acid Fracture Conductivity Using an Intelligent Model, Arabian J. Sci. Eng., 2016, 42, 1-8.

29 G. R. Dysart and N. F. Whitsitt, Fluid Temperature in Fractures, Presented at the Fall Meeting of the Society of Petroleum Engineers of AIME, New Orleans, Louisiana, USA, Jan 1, 1967. 